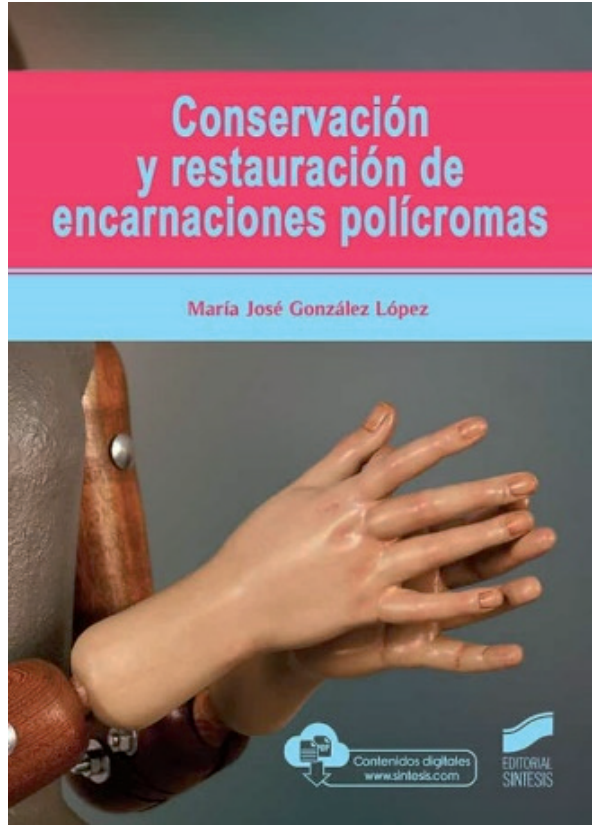

\section{Conservación y restauración de encarnaciones polícromas}

\author{
María José González López \\ Colección: Gestión, Intervención y Preservación del \\ Patrimonio Cultural (Guías prácticas) \\ Editorial Síntesis, S. A. Madrid 2020
}

ISBN 978-84-9171-457-6

Dimensiones: $21,30 \times 15 \mathrm{~cm}$

Páginas: 252

Idioma: Español
Con el título La Conservación y restauración de encarnaciones polícromas, el mercado editorial acoge un nuevo libro especializado en la conservación de bienes culturales. Su autora, Ma José González López, profesora titular del Grado de Conservación y Restauración de Bienes Culturales de la Facultad de Bellas Artes de la Universidad de Sevilla, añade con él nueva obra a su apreciable bibliografía sobre conservación del patrimonio cultural en el campo de la imaginería y la retablística española. La publicación corre a cargo de la editorial Síntesis y forma parte de su colección "Gestión, Intervención y Preservación del Patrimonio Cultural".

Se trata de una guía práctica dirigida a profesionales del campo de la conservación y está estructurada en tres capítulos. En ellos se desarrollan los diversos aspectos del muy particular universo de las encarnaciones de la imaginería en madera, que muestran la piel humana y que con sus técnicas específicas imitan las características tonales, texturales, morfológicas y expresivas de rostros, manos y pies desnudos. Sobre todo del cuerpo de los cristos, del niño Jesús o de la figura de San Sebastián, por ejemplo, donde la encarnación va a encontrar mayor superficie destinada a representar todos los matices de la piel humana. En la imaginería las encarnaciones son parte de esa búsqueda de la naturalidad que se afana en conmover la fibra más íntima del espectador. Su singularidad precisamente ha llevado en estos últimos años a resaltar esta parte de la policromía para contribuir a su conocimiento y reconocimiento y, por tanto, a su mejor y más rigurosa conservación. Entre estos trabajos destaca la publicación del encuentro de 2015 del ICOM-CC dedicado específicamente a las carnes: "Las encarnaciones de la Escultura Policromada", Sculpture, polycromy and architectural decorations Working Group Interin meeting, ICOM-CC - GEIIC, Madrid, November 1920, 2015, año de publicación 2018, pp. 273-300, donde la autora abordaba un interesante capítulo de esta técnica en la escultura barroca sevillana.

La primera parte de la obra de González López aborda el contexto histórico y cultural de esta técnica en España y Portugal, a través de las fuentes documentales de ambos ámbitos de la península, donde examina en detalle los tratados y tratadistas que aportan alguna información sobre las carnes pintadas, reuniendo aquí los resultados de sus trabajos anteriores. Describe y compara las distintas técnicas con las que se producían las encarnaciones a lo largo de varias centurias, y cierra el capítulo en el presente de una técnica que continúa viva en los talleres de los imagineros. Con los estudios aplicados al diagnóstico de las encarnaciones, la autora describe en una contundente segunda parte los agentes de deterioro y muestra en gráficos la clasificación de los indicadores visuales de alteración, a partir de los estudios realizados sobre el tema a lo largo de estas últimas décadas. Finalmente, la tercera parte de la guía comienza con los aspectos relativos a la conservación preventiva y el mantenimiento como actuaciones preferentes, siguiendo las recomendaciones de la literatura especializada incluidas a lo largo del capítulo. Continúa con una introducción sobre criterios de conservación y restauración, adentrándose en la fase operativa del proceso de conservación-restauración de las encarnaciones, que divide en tratamientos curativos y de restauración. Contexto en el que incidirá en las particularidades de los procedimientos de consolidación 
y fijación, limpieza, reintegración y barnizado final o protector de las encarnaciones. En esta última parte detalla técnicas, métodos y productos, con referencias a su origen y a los trabajos más recientes publicados, contrastados con las distintas teorías desarrolladas desde mediados del siglo pasado. La autora pone así en evidencia los cambios operados en el ámbito de la restauración, con el desarrollo de las ciencias aplicadas, al tiempo que examina tanto los métodos tradicionales como los actuales y el uso de cada uno de ellos con respecto a las carnes en la actualidad. La guía ofrece material complementario, disponible en la página web de la editorial asociada a cada trabajo publicado, donde se pueden descargar distintas fichas para el estudio específico sobre esta técnica, así como las que contienen ejemplos de estudios concretos sobre el tema abordado. 